\title{
Mulheres e maternidade: faces possíveis
}

\author{
Women and motherhood: possible faces
}

\section{La mujer y la maternidad: caras posibles}

\author{
Renata Feldman Scheinkman Lemos* \\ Pontifícia Universidade Católica de Minas Gerais - PUC Minas, Belo Horizonte, Minas \\ Gerais, Brasil
}

\section{Luciana Kind**}

Pontifícia Universidade Católica de Minas Gerais - PUC Minas, Belo Horizonte, Minas Gerais, Brasil

\begin{abstract}
RESUMO
Neste artigo, discutiu-se a maternidade contemporânea em uma dimensão plural, como acontecimento permeado de expectativas, ambivalências, antagonismos e prescrições de toda ordem. A pesquisa guiou-se por uma perspectiva ontológica do presente. Transformações no número de filhos, na vivência profissional, nos avanços tecnológicos e nos arranjos familiares são exemplos do que têm possibilitado à maternidade e à paternidade manifestarem-se em variados modos de existência. Esse contexto, de profundas transformações, ocorre em meio à lógica normativa, discursiva e tradicional que também rege a maternidade contemporânea. Diante desse cenário, a presente pesquisa perguntou a mulheres de diferentes perfis como elas se veem e como se sentem em relação à experiência de ser (ou não ser) mãe. O percurso metodológico baseou-se em uma pesquisa de campo de natureza qualitativa, realizada através de entrevistas semidirigidas a seis mulheres, sendo cinco mães e uma convicta em não sêlo. A análise dos dados teve como parâmetro a análise de conteúdo temática. Acredita-se que o presente estudo possibilitou investigar 0 diversificado olhar de mulheres para a maternidade contemporânea e suas várias possibilidades de existência, delineando dinâmicos processos de subjetivação diante das prescrições, expectativas e discursos que a acompanham.
\end{abstract}

Palavras-chave: maternidade contemporânea, mulheres, subjetivação.

\section{ABSTRACT}

This paper investigates the contemporary motherhood in a plural dimension permeated by all sorts of expectations, ambivalences, contradictions and requirements. The research was guided by an ontology of the present perspective. Transformations in the number of children, professional experience, technological advances and family arrangements are examples of what has made it possible for motherhood and fatherhood to be expressed in various modes of existence. This context of profound transformation occurs within the normative, discursive and traditional logic which also governs contemporary motherhood. Given this scenario, the 
present study asked women from different profiles how they see themselves and how they feel about the experience of being (or not being) mother. The methodological approach was based on a qualitative field research, carried out through semi-structured interviews with six women, five mothers, and one determined not to be. Data analysis had was carried on through thematic content analysis. This study made it possible to investigate the diversified ways through which women face contemporary motherhood and its various modes of existence, outlining dynamic subjectivation processes confronting the constraints, expectations and discourses that go along with being a mother.

Keywords: contemporary motherhood, women, subjectivity.

\section{RESUMEN}

Este trabajo investiga la maternidad contemporánea en una dimensión plural impregnaba las expectativas, las ambivalencias, contradicciones y exigencias de todo tipo, desde una perspectiva ontológica del presente. Los cambios en el número de niños, la experiencia profesional en los avances tecnológicos y los arreglos familiares son ejemplos de lo que ha hecho posible la maternidad y la paternidad manifiesta de diversos modos de existencia. Este contexto de profunda transformación se produce a través de la normativa, la lógica discursiva y tradicional que también rige la maternidad contemporánea. En este escenario, el presente estudio preguntó a mujeres de diferentes perfiles, ya que ven a sí mismos y cómo se siente acerca de la experiencia de ser (o no ser) madre. El enfoque metodológico se basó en una investigación de campo cualitativa, realizada a través de entrevistas semiestructuradas con seis mujeres, cinco madres y convencido de no ser. Análisis de los datos tuvo como parámetro para análisis de contenido temático. Se cree que este estudio ha permitido investigar la diversificada mirada de las mujeres para la maternidad contemporánea y sus diferentes posibilidades de existencia, destacando los procesos dinámicos de la subjetividad de los requisitos, expectativas y discursos que lo acompañan.

Palabras clave: maternidad contemporáneo, mujeres, subjetividad.

\section{I ntrodução}

As formas de tornar-se mãe na contemporaneidade são permeadas de expectativas e prescrições de toda ordem. A primeira grande determinação diz respeito à própria decisão de se ter ou não um filho, considerando-se as camadas sociais médias, foco deste artigo. Durante décadas - e ainda hoje - a figura da mulher é culturalmente vinculada ao papel de mãe, a despeito da contribuição dada pelos movimentos feministas. É como se a decisão de engravidar não precisasse ser pensada pela mulher, pois é tido como natural que isso aconteça e que ela cumpra sua missão biológica. Assim, o que poderia ser uma escolha torna-se quase que uma "imposição": ter que engravidar. Para as mulheres escolarizadas, com grau superior completo, esta "necessidade" parece ser vivida de maneira conflitante, já que muitas vezes se adia a maternidade para se dedicar à construção de uma carreira profissional. Apesar de que a escolha por não ter filhos seja algo mais explícito nos dias de hoje, 
muitas mulheres ainda se veem diante da "imposição" da maternidade.

A construção da subjetivação materna é acompanhada do imperativo da locução verbal "ter que", com diferentes complementos: ter que engravidar, ter que amamentar, ter que brincar com os filhos, ter que ser ao mesmo tempo mulher, mãe, profissional e dona de casa. É preciso ainda corresponder ao ideal de mãe perfeita, dedicada, heroína, santa, que a cultura ajudou a construir: “(...) a mãe deve ser alegre, feliz, tranquila, serena, ajustada, sem hostilidades, angústias ou conflitos - conscientes e inconscientes -, atenta às mínimas inquietações que a afligem, para saná-las imediatamente." (Novelino, 1988, citado por Stasevskas, 1999, p. 6). Estas cobranças decorrem de certo equívoco em atribuir às mulheres, em função dos aspectos biológicos que a tornam mãe, a responsabilidade quase que exclusiva de exercer a maternagem, produzindo identidades préfabricadas para o universo feminino. E como se não bastasse "ter que" ser mãe, esta mãe "tem que" ser uma boa mãe para ser feliz e se realizar plenamente. (Stasevskas, 1999).

Ao observar mães brincando em um parquinho em Nova York, Druckerman (2013) registra uma intensa e excitada sequência de falas das mulheres com seus filhos e filhas, denominada de "narrativas de brincadeiras". Apesar de considerar essas narrativas nonsense, a autora afirma que através destas esfuziantes interações, as mulheres mostram o quanto são boas mães.

Gutman (2013) chama a atenção para a questão de identidade e autoestima que muitas vezes permeia a função materna, afirmando que além dos cuidados inerentes à criação dos filhos há também "a nossa necessidade de sermos reconhecidas, de nos sentirmos vivas ou valiosas à medida que somos indispensáveis para o outro" (Gutman, 2013, p. 117).

Diante do descompasso entre o que a sociedade contemporânea espera da maternidade e a forma como é efetivamente vivida permeada de ambivalências, conflitos e antagonismos -, pode-se pensar em modos multifacetados de subjetivação materna. Essa perspectiva encontra sustentação teórica em Foucault (1984/2003) e no que ele chamou de "jogos de verdade", investigando a constituição histórica do sujeito enquanto experiência vinculada aos campos do saber, da normatividade e da subjetividade. Ao buscar compreender de que forma o sujeito entra nos jogos de verdade, 0 autor percebe que esta relação é estabelecida através de práticas de si. (Foucault, 1984/2004). Em paralelo com as considerações do autor, nos propomos a indagar: através de quais jogos de verdade são constituídas as experiências de maternidade nos dias de hoje?

Pensar os modos de existência no tornar-se mãe contemporâneo implica pensar o sujeito e suas formas de se colocar no mundo. Para Rose (2011, p. 137), esta análise transcende a ideia de interioridade 
e singularidade associadas ao eu e ganha uma dimensão de pluralidade e diversidade socialmente construída, explicada de forma contundente pelo autor: "[a] ideia de 'eu' entrou em uma crise que pode muito bem ser irreversível." Rose (2011) discorre sobre as críticas a perspectivas teóricas que se pautam por uma configuração do sujeito como "universal, estável, unificado, totalizado, individualizado, interiorizado."

No entanto, apesar de que a dimensão de pluralidade seja legitimada e apropriada pelos teóricos sociais, como menciona Rose (2011), é possível perceber algumas práticas regulatórias que persistentemente definem os sujeitos como se fossem especificidades categorizadas como certos eus - o "eu-mãe", o "eu-pai", "eu-filho/a", "euprofissional", "eu-mulher". Assim argumenta Rose:

$\mathrm{Na}$ vida política, no trabalho, nos arranjos domésticos e conjugais, no consumo, no mercado, na publicidade, na televisão e no cinema, no complexo jurídico e nas práticas da polícia, nos aparatos da medicina e da saúde, os seres humanos são interpelados, representados e influenciados como se fossem eus de um tipo particular: imbuídos de uma subjetividade individualizada, motivados por ansiedades e aspirações a respeito de sua autorrealização, comprometidos a encontrar suas verdadeiras identidades e a maximizar a autêntica expressão dessas identidades em seus estilos de vida. (Rose, 2011, p. 137-138).

Em evidência na mídia, nas diversas possibilidades terapêuticas e na voz dos especialistas, a psique ganha respaldo e causa identificação, pois as pessoas se reconhecem na problemática do eu a que assistem sistematicamente interpretada. Este parece ser um movimento de "psicologização", em convergência com o questionamento de Rose (2011), que discute como o individualismo da sociedade ocidental moderna tem produzido indivíduos "comprometidos com o objetivo de moldar um significado para suas vidas por meio da maximização de uma 'qualidade de vida' pessoal." (Rose, 2011, p. 139).

Ao se deter sobre o "modo pelo qual um ser humano torna-se um sujeito", Foucault (1995, p. 232) percorre ainda as relações de poder e as várias possibilidades de oposição e resistência concernentes ao tema. Foucault (1984/2003) apresenta sua genealogia das práticas de si na cultura greco-latina como forma de problematizar a correlação entre "campos de saber, tipos de normatividade e formas de subjetividade" (p. 10). Nesse sentido, dedica-se ao estudo das "artes da existência", ou do trabalho ético do sujeito sobre si mesmo. 
Em suas palavras, por contraponto com as "regras de condutas" das prescrições morais, o filósofo se interessava pelas "diferentes maneiras, para o indivíduo que age, de operar não simplesmente como agente, mas sim como sujeito moral dessa ação." (Foucault, $1984 / 2003$, p. 27). É na relação do sujeito consigo mesmo especialmente através do preceito do cuidado de si - que Foucault (1984/2002, 1984/2003; 1981-1982, 2006) pauta sua reflexão para pensar modos de subjetivação. Apesar do pronome reflexivo si, indicativo de um movimento de introspecção e individualidade voltado para o eu, o cuidado de si abarca toda uma relação com a alteridade. Nas palavras de Foucault (1984/2002, p. 57), "tem-se aí um dos pontos mais importantes dessa atividade consagrada a si mesmo: ela não constitui um exercício da solidão, mas sim uma verdadeira prática social." O preceito revela-se em uma forma de se conduzir na vida: nas atitudes, posturas, comportamentos, maneiras de agir e se relacionar com o outro.

Em diálogo com Foucault e outros autores que problematizam a subjetividade como construção identitária, interiorizada, essencializada, estão Méllo e Di Paolo (2007). Os autores sintetizam as reflexões teóricas nessa direção argumentando que, embora apresente experiências de um "si", a subjetivação se constitui em "redes de negociações sociais que produzem efeitos de indivíduos ou sujeitos, ou simplesmente modos de ser." (p. 133)

Tendo em vista esse apoio teórico para pensar modos de subjetivação, buscou-se acessar e compreender a maternidade nos dias de hoje, assinalando-se os diversos modos de construção de subjetivação de mulheres diante da maternidade. Enfatiza-se, portanto, a dimensão plural do tornar-se (ou não) mãe.

\section{A maternidade no Contexto Familiar Brasileiro}

Sem perder de vista o recorte social adotado pelo presente estudo, deparamo-nos com grandes mudanças envolvendo a família de classe média brasileira e os principais temas que a permeiam: casamento, filhos, trabalho, separação, divórcio e a própria maternidade, intensamente "metamorfoseada" ao longo dos séculos.

Desde o final do século XVIII, um conjunto de grandes mudanças afetou as mulheres de forma impactante, segundo Giddens (1993, p. 53): a criação do lar, a mudança na relação entre pais e filhos, "a invenção da maternidade." Coelho (2006) explicita as muitas transformações ocorridas na família brasileira nas últimas décadas. Da dicotomia público-privado, envolvendo um modelo ideal-patriarcal de hierarquização e poder do homem frente à mulher e aos filhos, veio o ideal igualitário e a flexibilização dos papéis atuantes. Do trabalho feminino restrito ao lar, considerando-se ainda as classes 
médias, surgiu a presença de mulheres no mercado de trabalho e na esfera pública. Do casamento vieram o divórcio e os novos arranjos familiares - monoparentais, homoafetivos, alternativas à coabitação, dentre outros arranjos. Dos movimentos feministas veio uma nova reflexão e prática do que é ser mãe: a simples possibilidade de não a ser. Coelho (2006) assinala que não ser mãe, como uma proposta de constituição de si como mulher, afirma-se com a desnaturalização da maternidade. Como posicionamento, não ser mãe abre caminho "para a liberdade de uma vida íntima, não ligada à relação conjugal", afirma Coelho (2006, p. 158).

\subsection{Maternidades e contemporaneidade}

Na era digital, os bebês já nascem no Facebook, através das fotos e textos instantaneamente compartilhados. Várias maternidades também comunicam os nascimentos através da internet, inserindo fotos dos recém-nascidos nas suas páginas institucionais. Antes mesmo de nascer, a criança é apresentada à mãe pela imagem capturada do ultrassom. Os recursos tecnológicos avançam a cada ano, possibilitando que até mesmo as expressões faciais do bebê sejam registradas no formato tridimensional.

Além de alojar "ritos dotados de uma significação sentimental" (Martin-Fugier, 1991, citado por Spink, 2010, p. 47), a grande rede sociotécnica - que substancializa modos de ser mãe - também atua como instrumento prático-funcional. Algumas mulheres fazem carreira, cuidam dos filhos, gerenciam a casa e trocam experiências da maternidade no mundo virtual. Em sua tese, intitulada De Maria a Mary - Mulheres em transição na experiência contemporânea da maternidade, Lima (2005) faz menção a essa virtualidade a partir de uma reportagem publicada no J ornal O Globo em maio de 2001. Com o título "Mamãe é Virtual", a matéria aborda a comunicação de uma executiva de 36 anos com os seus dois filhos de 9 e 10 anos, com quem se encontra presencialmente apenas nos finais de semana. Este foi o trecho da matéria utilizado pela pesquisadora:

É uma típica mãe virtual, que explica aos filhos os deveres de casa por e-mails e faz recomendações do tipo "escovem os dentes", "arrumem o quarto"... A mãe contemporânea é assim: tão múltipla que sua versão on-line se soma à presença real no fim de semana. (Lima, 2005, p. 149)

De uma maneira geral e não absoluta, foram-se as fraldas de pano, as amas de leite, a mãe em tempo integral como algo inquestionável. Ficaram, para algumas mães, a dificuldade de amamentar, a palavra dos especialistas e os conflitos levados à psicoterapia. O tempo e dedicação às tarefas de cuidado e ao trabalho envolvem negociações 
de toda ordem com parceiros/as, empregadores/as e com as próprias fantasias do que é ser uma "boa mãe".

Um conflito permanente para mães de classe média é a dificuldade posta por algumas mulheres em conciliar a vida materna com a profissional. Gutman (2013) faz uma reflexão interessante sobre o paradoxo que parece ter se instalado entre a merecida conquista histórica do trabalho feminino e a dificuldade de conciliá-lo com a maternidade. As mulheres foram às ruas, lutaram por um lugar no mercado de trabalho e este lugar agora é questionado quando se alcança também o lugar de mãe. Na visão da autora, porém, o foco dessa discussão não reside na vida profissional, mas na maternagem em si, nas exigências de cuidados de crianças pequenas que as próprias mulheres podem, por vezes, assumir como incompatíveis com o trabalho.

Druckerman (2013) analisa a culpa materna a partir de um contraponto entre as mães francesas e americanas. Estas últimas vivenciam o sentimento como mecanismo de recompensa. A autora afirma que a culpa, para as mães americanas é uma espécie de "imposto emocional" para o investimento no trabalho. Em tom irônico, a autora sintetiza: "[não] somos simplesmente egoístas. Nós 'pagamos' por nossos lapsos." (Druckerman, 2013, p. 143)

Já para as mães francesas, segundo a autora, a culpa não tem - ou não deveria ter - este peso e valor. Elas costumam se tranquilizar com o pensamento de que "a mãe perfeita não existe", desconstruindo a própria "necessidade" de se ter culpa. Na visão de Druckerman (2013, p. 143), "[o] que realmente fortifica as mulheres francesas contra a culpa é a convicção de que não é saudável para as mães e para as crianças passarem o tempo todo juntas."

Badinter (2011) tece alguns contrapontos em relação às grandes transformações ocorridas na maternidade nos últimos 30 anos, nos levando a refletir acerca de alguns modos de ser mãe na contemporaneidade: o retorno ao modelo tradicional, naturalista e instintivo, versus a possibilidade de escolher exercer ou não a maternidade; os desejos de mulher versus os deveres de mãe; a maternidade versus a liberdade, em um contexto hedonista. Esses contrapontos acabam evidenciando as ambivalências da maternidade e apontam para uma nova forma de subjetivação materna. Badinter (2011, p. 21) pondera que os ideais de amor e felicidade que acompanham o projeto de tornar-se mãe "ignora a outra face da maternidade, a que é feita de esgotamento, de frustração, de solidão e até mesmo de alienação com seu cortejo de culpabilidade."

Contradizendo a tese de Badinter (2011) que postula a existência de um conflito entre a mulher e a mãe, as "Marias" entrevistadas por Lima (2005) expressaram uma forte junção entre as identidades feminina e materna ao serem abordadas sobre o que é ser mulher. As mulheres entrevistadas por Lima tomam "mãe" e "mulher" como 
termos redutíveis um ao outro, com um movimento metonímico que naturaliza a maternidade como destino unívoco para as mulheres. Gutman (2013) localiza nessa equivalência absoluta entre mãe/mulher um "conflito de identidade", na medida em que acompanha a experiência de maternidade uma constante busca de retorno ao que se era antes. "Nosso 'eu' se perdeu no meio das fraldas", ironiza a autora (Gutman, 2013, p.101).

Ao situar a mãe na contemporaneidade, Badinter chama a atenção para uma época pautada pelo narcisismo, individualismo, hedonismo: "[numa] civilização onde o 'eu primeiro' é elevado a princípio, a maternidade é um desafio, quiçá uma contradição." (Badinter, 2011, p. 20). Essa reflexão confirma o postulado de Rose (2011) em relação às categorizações individuais do eu ("eu-mãe", "eu-pai", "eu-filho", etc.) a despeito da dimensão de pluralidade e diversidade socialmente construída que compõe os modos de existência.

\section{Método}

O presente estudo contempla a realização de uma pesquisa qualitativa, caracterizada por se fundamentar teórica e empiricamente na compreensão de modos de ser (e não ser) mãe na contemporaneidade. Como instrumento, utilizou-se a entrevista semidirigida que tinha como ponto de partida uma única frase norteadora: "O que é ser mãe para você?" A partir dessa questão inicial, foram produzidas questões imanentes ao longo da entrevista, como proposto por Jovchelovitch e Bauer (2002). Embora o estudo não tivesse um contorno exclusivo de pesquisa narrativa, o modo de condução das entrevistas buscou produzir uma inflexão específica para que as entrevistadas contassem sua experiência de tornar-se (ou não) mãe.

Em consonância com o embasamento teórico e a práxis de uma das autoras como psicóloga clínica, foram delineados critérios de inclusão na construção de "mulheres possíveis" que antecipariam múltiplas faces sobre a maternidade, considerando-se: mães em diferentes situações conjugais; mães trabalhadoras em período parcial ou integral; mães que optaram por não trabalhar, dedicando-se em tempo integral à experiência materna; mulheres que optaram por não ser mãe.

A identificação destas mulheres foi realizada através de indicações feitas na rede pessoal de contatos das pesquisadoras. De modo correspondente aos critérios de inclusão, foram entrevistadas seis mulheres mineiras de classe média, todas residentes na cidade de Belo Horizonte, como disposto no Tabela 1. Os nomes de pessoas e instituições mencionados na Tabela 1 e nos fragmentos das 
entrevistas que serão expostos adiante são fictícios, de modo a não identificar as mulheres envolvidas no estudo.

Tabela 1

Caracterização das entrevistadas

\begin{tabular}{|c|c|c|c|c|}
\hline Entrevistada & Idade & Filhos & $\begin{array}{l}\text { Situação } \\
\text { conjugal }\end{array}$ & $\begin{array}{c}\text { Situação } \\
\text { profissional }\end{array}$ \\
\hline Juliana & 32 anos & $\begin{array}{l}\text { Bruna, } 6 \text { anos } \\
\text { Rafael, } 3 \text { anos }\end{array}$ & Casada & Horário parcial \\
\hline Teresa & 41 anos & Raquel, 6 anos & Divorciada & Horário integral \\
\hline Nina & 35 anos & $\begin{array}{l}\text { Letícia, } 5 \text { anos } \\
\text { Sofia, } 2 \text { anos }\end{array}$ & Casada & $\begin{array}{l}\text { Dedicação } \\
\text { exclusiva às filhas }\end{array}$ \\
\hline Patrícia & 42 anos & $\begin{array}{l}\text { Opção por não } \\
\text { ter filhos }\end{array}$ & $\begin{array}{l}\text { Relação } \\
\text { conjugal } \\
\text { estável }\end{array}$ & Horário integral \\
\hline Vanessa & 31 anos & $\begin{array}{l}\text { Henrique ( } 10 \\
\text { dias); gestante } \\
\text { de } 5 \text { meses à } \\
\text { época da } \\
\text { entrevista }\end{array}$ & Casada & Horário integral \\
\hline Carla & 37 anos & $\begin{array}{l}\text { Eduardo, } 9 \text { anos } \\
\text { Matheus, } 6 \text { anos } \\
\text { Vitor e Thiago, } 4 \\
\text { anos }\end{array}$ & Casada & $\begin{array}{l}\text { Estudante } \\
\text { universitária }\end{array}$ \\
\hline
\end{tabular}

Fonte: Elaborado pelas autoras.

Como forma de realizar uma leitura analítica dos dados colhidos, elencou-se a análise de conteúdo, delineada por Bardin (2011) como um importante recurso de análise das formas variadas de comunicação. No caso do presente estudo, esta abordagem concentrou seu foco na análise temática de dados, que pode ser entendida como uma das possibilidades derivadas da análise de conteúdo clássica, conforme esclarece Bardin (2011). Esta abordagem permitiu às pesquisadoras investigar a questão da maternidade contemporânea em suas múltiplas facetas, contemplando vivências, percepções, singularidades e o cotidiano das mães implicadas na pesquisa. 


\section{Resultados e Discussão}

Diante do processo sistemático de codificação e categorização, tendose como horizonte as várias faces da mãe contemporânea e a diversidade dos sujeitos de pesquisa, foram produzidas cinco categorias assim nomeadas: Dedicação, Normatividade, Esgotamento, Conflitos e Ambivalências, Transformações.

Partindo da premissa de que múltiplos são os processos de subjetivação, referendados neste estudo principalmente pelo olhar foucaultiano, os resultados apresentados a seguir nos conduzem a analisar modos de subjetivação relacionados ao tema da maternidade.

\subsection{Dedicação}

Das seis mulheres entrevistadas, todas abordaram a temática da dedicação materna, inclusive Patrícia, que optou por não ser mãe. Pode-se perceber, através dos depoimentos colhidos, relatos de priorização absoluta dos filhos, muitas vezes em detrimento de outros projetos e interesses. Dentre as entrevistadas, Nina direcionou-se para ser mãe em tempo integral. Ela nos diz: "ser mãe para mim tá em primeiro lugar. Tá tudo em torno delas, assim, os interesses, tudo que tá me movendo tá em torno delas. Já Juliana, que trabalha em regime parcial de horário, formula do seguinte modo o tipo de dedicação de que dispõe:

A gente coloca os filhos acima de tudo, né? Então aí você vê que planos que eu tinha e que para mim eram essenciais hoje eu vejo que aquilo não vai trazer felicidade nenhuma. Que é melhor tá ao lado dos meus filhos [...] ter um emprego que: me dê um tempo pra dar uma dedicação a eles que isso pra mim hoje é o essencial. Eu acho que a mãe que quer se dedicar ao filho acaba abrindo mão de alguns planos.

Essa face dedicada da mãe contemporânea revela-se antagônica em relação às mães francesas dos séculos XVII e XVIII que deixavam os filhos entregues aos cuidados das amas de leite, denotando indiferença em relação ao filho, segundo análise de Badinter (1985). Ou, segundo Mello (2011), se contrapõe àquelas que eram persuadidas por moralistas, médicos e administradores a desenvolver os cuidados maternos, já que estes eram tidos como um estorvo por elas.

Esses contrapontos vêm confirmar uma mudança expressiva nos modos contemporâneos de ser mãe, especialmente sobre o aspecto da dedicação aos filhos. Na tentativa de compreender o ponto nevrálgico da transição entre a indiferença e a dedicação extrema, 
encontramos em Collin e Laborie (2009) um divisor de águas: a ideologia rousseauniana do amor materno (1760-1978), que repercute até hoje através de um forte valor atribuído à mãe, vista como aquela que cuida, que zela, que coloca o filho acima de tudo.

Se a dedicação se apresenta como uma das faces da mãe contemporânea, ela parece se apoiar veementemente nessa ideologia, reforçando todo um movimento de idealização e enaltecimento da figura da mãe. Ao se dedicar inteiramente aos filhos, como revelam os dados da pesquisa, as mães contemporâneas demonstram incorporar as marcas de "super mãe" ou "santa mãe", fazendo jus a uma imagem construída e idealizada desde o século XVIII.

Cabe aqui retomarmos Badinter (2011) e sua reflexão sobre o antagonismo estabelecido entre os desejos de mulher e os deveres de mãe, tão ressaltados na pesquisa pelo que mostra a face da dedicação. Chama atenção também o dilema colocado pela autora da maternidade versus liberdade em um contexto hedonista, claramente situado por Patrícia na sua posição de não-mãe. A entrevistada faz uma crítica veemente às mulheres que passam a maior parte do dia no trabalho, "terceirizando" os cuidados dos filhos junto a babás ou escolas. Se ela fosse mãe, pondera Patrícia, a situação seria diferente:

Olha, eu vou te falar das mães de hoje, que é a maioria das mulheres que tem que trabalhar oito horas ou até mais por dia. Eu tenho dó delas, sabe? Eu acho que se eu tivesse um filho eu ia querer NO MíNIMO ou ser autônoma ou trabalhar no esquema de meia hora. Eu não acho que... uma mãe que fica oito horas por dia dentro de um escritório e depois tem mil outras atividades que deixa o filho com a babá ou na escolinha... ela... cumpre o papel de mãe, mas... não vamos ser também utópicas, né, é o que acontece hoje. Eu não gostaria de ser uma mãe assim, sabe? Uma coisa que é fato, que se eu tivesse um treco, vou ter um filho de todo jeito seria isso, me embasar para ter condição de dedicar NO MíNIMO metade do meu dia e a noite inteira para isso... e não ficar essa coisa aí, cê ter a correria, acorda com o filho, nem viu o menino direito, dá uma comidinha já despacha põe na escolinha, depois enfia ele em MIL atividades, né?

Apesar da posição convicta em não ser mãe, Patrícia coloca essa possibilidade como hipótese, caso venha a ter "um treco". No seu exercício de imaginação, a entrevistada vislumbra um cenário bastante convencional da maternidade, em que o tema da dedicação tem importante destaque. Embora veja com naturalidade o fato de não querer ser mãe, Patrícia recrimina as mães que comprometem a 
dedicação dos filhos em função de trabalharem fora. Há certo contraponto, então, entre a atitude não convencional de escolher não ser mãe (percebida por ela como algo natural) com a atitude convencional de dedicar mais tempo dos filhos.

\subsection{Normatividade}

Seguir preceitos, regras, estar "dentro da normalidade" é algo que se mostra presente na fala dos sujeitos de pesquisa, com exceção de Patrícia. Na visão das cinco mães entrevistadas, a maternidade é o caminho "natural", primeiro grande preceito a ser seguido. É o que se pode confirmar através da fala de Carla:

Eu sempre vivi em contextos em que a família sempre foi muito valorizada mesmo vivendo parte em zona rural da minha vida, da minha infância e outro momento é: na cidade. Então isso sempre foi trazido. E eu sempre cresci com isso, com esses ensinamentos: "tem que estudar, tem que crescer, tem que ser criança, tem que estudar, tem que arrumar [namorado], namorar, arrumar um marido, casar e ser mãe". É o ciclo natural...

É possível inferir, pelo depoimento de Carla, que o que ela percebe e defende como "natural" é visto, neste trabalho, como um conjunto de convenções sociais preconizadas para o universo feminino. Pelo depoimento de Carla, a decisão de ser mãe parece ter vindo "de fora", dos valores e ensinamentos transmitidos como tradição familiar, interiorana, numa apreensão normativa da maternidade. Já para as feministas da corrente igualitária, segundo Scavone (2001), a "norma" que condicionava a mulher a ser mãe era duramente combatida, numa tentativa de desconstruir o biologicismo reducionista que determinava às mulheres o lugar de gestante, parturiente, puérpera e nutriz, confinando-as ao espaço privado e consequentemente isolando-as do espaço público.

Já na visão de Patrícia, engravidar não tem que ser uma regra. Ao ser questionada se é uma não-mãe convicta, ela respondeu que "sim, absolutamente; convicta e tranquila, sem achar que sou uma pessoa anormal". Com uma argumentação combativa, Patrícia emite sua posição diante de perspectivas que naturalizam a maternidade como missão das mulheres.

Eu acho anormal a mulher que me acha uma aberração por não querer ter filho porque acha que uma mulher não é completa se não for mãe. Eu tenho Dó de uma pessoa que pensa assim porque/ dela e do filho dela, porque ela transfere uma carga para um ser que nem nasceu ainda da frustração que ela tem 
com ela própria. Eu não tenho isso, sabe? Por exemplo, eu fui visitar semana passada um nenenzinho de um grande amigo, fui levar meu presente, essas coisas normais, sou uma pessoa normal ((riso)). E na hora que ele me deu para pegar, tão pequeninho, me deu uma agonia assim, eu peguei com todo carinho, cuidado e etc., mas não é aquele negócio que eu fico à vontade ali, achando tranquilo, entendeu é... sei lá... eu ainda brinquei com ele, é, que o nenenzinho começou a rir para mim, eu falei: "Não adianta, eu não quero um desse (lá) pra mim, isso é fato". ((risos))

Patrícia nos convida a pensar a dimensão da maternidade como "exercício" que se aprende e pratica através de ações tipicamente maternas, como pegar no colo, carregar, brincar, rir e interagir através do afeto. Ao fazer algo "normal" ("visitar um nenenzinho de um grande amigo, fui levar meu presente, essas coisas normais, sou uma pessoa normal"), Patrícia se vê diante do estranhamento e desconforto de lidar com um bebê, o que para outras mulheres especialmente as que escolheram ser mães - pode ser algo pleno de sentido e familiaridade.

Nas suas "simulações maternas", ainda que não muito à vontade, Patrícia reconhece (e por isso ri e se contrapõe) que segurar o bebê, brincar, capturar afeto condizem com um "exercício da maternidade" a qual ela não se sente integrada. O desconforto percebido com essas práticas tão maternas sinaliza a confirmação de uma escolha que exclui, para essa mulher, a possibilidade de vir a se tornar mãe.

Ao se deparar com o "exercício da maternidade", Patrícia acaba praticando um "exercício sobre si mesma", o que também significa, em um viés foucaultiano (1984/2004), conhecer-se a si mesma. E a esse processo corresponde conhecer ainda "um certo número de regras de conduta ou de princípios que são simultaneamente verdades e prescrições." (Foucault, 1984/2004, p. 269).

\subsection{Esgotamento}

Diante de tantas prescrições, dedicação e responsabilidade (muitas vezes convertida em culpa), as mães entrevistadas revelam a face do esgotamento. Seja no puerpério, na gestação ou em uma fase em que as crianças já estão mais crescidas, percebe-se um desgaste físico, mental e emocional. Mesmo sendo uma "mãe em tempo integral", Nina reconhece os excessos do seu cotidiano: "não existe sábado, domingo nem feriado... Não dormia, não dormia, eu quase enlouqueci, assim de cansaço."

Esmiuçando a decisão dessa mãe em suprimir a vida profissional para se dedicar inteiramente à maternidade, nos cabe deter um pouco mais sobre esse movimento de renúncia. Num movimento contrário 
ao das feministas que lutaram para ingressar no mercado de trabalho (Badinter, 2011; Collin \& Laborie, 2009; Souza, 2013), Nina "renuncia ao cargo", evidenciando mais uma vez o peso da dedicação aos filhos na maternidade. Podemos inferir, com isso, que passa a haver uma transferência das relações de poder no âmbito profissional para o familiar e doméstico.

Eu tenho uma babá que me ajuda, hoje eu tô com uma babá, mas eram duas babás que/ que/ que moravam/ que trabalhavam aqui em casa e uma morava, uma ficava exclusivamente de segunda a sexta dormindo, tinha uma outra que dava suporte diário e no final de semana tinha uma outra que entrava. Então eu tinha pessoas me ajudando o tempo todo. Nunca tive, graças a Deus, e a gente teve uma condição financeira pra... poder organizar isso porque senão não seria fácil. [...] eu acho que eu não conseguiria é... conciliar o cuidado das quatro crianças com qualquer outra coisa, diferente disso, que eu viesse a fazer externamente. Então a gente consegue conciliar tudo com a ajuda/ eu tenho uma pessoa que me ajuda na organização da casa e uma pessoa hoje que me ajuda com as crianças.

Mãe de quatro filhos, com idades entre 4 e 9 anos, Carla nos ajuda a pensar agenciamentos importantes na configuração de certos modos de ser mãe. Apoio, ajuda, suporte e estrutura são palavras que integram um modo de subjetivação materna importante, que se percebe por Carla. Não se trata, aqui, de enviar os filhos para amas de leite, como acontecia no passado historicizado por Badinter (1985) nem para a casa das avós, o que confirma a "ausência das figuras femininas importantes na escala familiar", segundo Polity e Balestrero (2008, p. 118). Trata-se da díade mãe-e-babá que, apesar de não configurar uma experiência universal, revela-se aqui como um modo importante de construção da maternidade.

A díade mãe-e-babá parece sugerir, portanto, uma pluralidade fluida e dinâmica, movida por um complexo sistema de agenciamentos. Assim a subjetividade foi delineada por Rose (2011) em consonância com Deleuze, sendo tomada muito mais pelo que o indivíduo pode fazer do que o que ele/a é. E o que ele/a faz - consigo mesmo e diante da alteridade que o/a cerca - está imbricado, como no caso de Carla, em um complexo sistema de relações, forças, práticas e conexões que dão o tom da subjetividade materna.

\subsection{Conflitos e ambivalências}

Ao lado da felicidade, realização e plenitude que compõem a experiência da maternidade contemporânea, manifestam-se também 
outros sentimentos como medo, preocupação, tristeza, aflição, desespero, frustração. Pelo relato de Teresa, estas ambivalências culminaram em uma depressão pós-parto.

E aí quando ela nasceu eu não sabia o que fazer com aquele neném, uma menina linda, fofa, e eu tive uma mistura de sentimentos, ao mesmo tempo que eu achava aquela coisa assim, mais divina, né, uma bênção eu ter conseguido realizar, eu morria de medo, de não saber cuidar e encaminhá-la. Então o que hoje eu posso dizer que é... difícil... é equilibrar essas duas coisas é, de ter que trabalhar, ser profissional, e ser boa mãe, e tá com ela, eu viajo, eu preciso ficar fora, mas tenho que tá presente nos momentos mais importantes, né, então eu faço uma ginástica na minha agenda pra: passar no máximo um dia fora de casa só, ou uma noite, pra que ela não sinta é... ou sinta menos, né.

Além do equilíbrio, mencionado por Teresa para abordar dessa vez o conflito mãe-profissional, a entrevistada também remete a uma questão extremamente relevante: a maternidade, ou melhor, os sentimentos vinculados a esta experiência constituem um processo amplo e contínuo de aprendizagem.

O depoimento de Teresa atesta que se aprende a ser mãe. Aprendese através do outro e do cuidado de si que pressupõe essa alteridade, através de uma ascese, por analogia ao que foi pensado por Foucault (1984/2008). Aprende-se pela atitude de modernidade que implica "tomar a si mesmo como objeto de uma elaboração complexa e dura [...], conforme formulou o filósofo em seu diálogo com Baudelaire (Foucault, 1984/2008, p. 344).

No olhar de Vanessa diante do filho que ainda não nasceu, sentimentos de medo, pavor e insegurança contrastam com a segurança, firmeza e autoconfiança:

A gente tem dúvidas, a gente tem medos. Eu não sei se eu sei trocar uma fralda, eu não sei se... eu tenho pavor do engasgar. Então eu tenho pavor do [...] bebê perder a respiração e eu não saber o que fazer... dormindo ou alimentando, a gente ouve muitas histórias. E ao mesmo tempo eu tenho muita segurança. Eu falo que é muito louco isso porque: eu preciso da minha mãe perto pra poder me mostrar o que fazer, mas ao mesmo tempo eu tenho certeza que na hora que ele nascer eu vou querer pegar e eu vou achar que eu sei cuidar dele melhor que minha mãe ou minha sogra, então eu tenho esse sentimento que eu vou querer ela do meu lado ali, mas eu acho que eu vou querer pegar, que eu vou querer fazer, sabe? 
Os fragmentos das entrevistas com Teresa e Vanessa alinham-se à concepção de subjetividade aventada por Rose (2011, p. 234), como algo que reflete o sujeito "como socialmente construído; como dialógico; como inscrito na superfície do corpo, como espacializado, descentrado, múltiplo, nômade; criado em práticas episódicas de autoexibição, que buscam reconhecimento em espaços e tempos particulares." Longe de serem, portanto, mães prontas, fixas, universais e individualizadas, Teresa e Vanessa aprendem a ser mãe de forma plural e diversificada, a partir das suas várias conexões e agenciamentos.

\subsection{Transformações}

O aspecto transformador da maternidade surge no presente estudo como algo inevitável, constituindo a experiência um divisor de águas na vida dessas mulheres. Todas as entrevistas pontuaram mudanças vividas com a maternidade. Teresa expressa com veemência o sentido de transformação emocional que a maternidade acarretou na vida dela, tornando-a uma pessoa melhor depois da filha.

Eu fui percebendo que pra gerar esse amor incondicional, pra aprender a ter esse amor incondicional, experimentar isso eu precisava melhorar como pessoa e aí comecei uma viagem maior de autoconhecimento pra identificar aquelas minhas imperfeições que pudessem de alguma forma, dificultar o relacionamento com a minha filha, ou até dificultar a minha... avaliação, minha/ minha performance como mãe né, então esse é um trabalho que eu tenho feito diariamente comigo, né, como o trabalho tem que ser muito ativo e muito ágil em casa eu procuro ser mais serena, mais calma... e é uma dificuldade pra mim, é difícil ter que equilibrar essas coisas, né, mas eu tenho tentado trabalhar as minhas imperfeições pra ser um bom exemplo pra minha filha como pessoa, desejo que ela se inspire em mim por eu ser uma pessoa do bem. (...) A gente fica menos egoísta, pra mim aconteceu assim, eu acho que eu sou menos egoísta, sou menos orgulhosa, é... e assim, tenho muito mais facilidade e... não tenho dificuldade assim, em renunciar alguma coisa que seja pro bem estar dela...

Gerar, aprender, experimentar. Através dessa significativa sequência de verbos, Teresa conjuga esforço e empenho ao exercer sua maternidade, transformando-se no sentido de ser uma pessoa melhor. Para ela, a vivência da maternidade se expressa como uma estética da existência; um caminho foucaultiano (1984/2003) de se perceber no mundo através do exercício reflexivo de práticas transformadoras em que o fim último consiste em ser alguém melhor. 


\section{Faces que se encontram: considerações finais}

Os resultados aqui apresentados reafirmam a diversidade do olhar feminino diante da maternidade contemporânea. Como num grande mosaico em movimento, as faces da mãe contemporânea se deslocam, se interpenetram, se sobrepõem e se encontram, desencontrando-se novamente. Retomando as considerações de Rose (2011), perfazem agenciamentos e conexões que formam e transformam a subjetividade materna diante de uma atualidade que também é revestida de passado. Hoje e ontem se encontram, muitas vezes de forma ambivalente e conflituosa na experiência da maternidade. O tecnicismo contemporâneo, com todos os seus apelos e inovações, gera uma nova forma de pensar e construir a subjetividade, sem, no entanto, se desprender da força da tradição. É o que nos confirma Foucault $(1971 / 2002)$ ao ponderar que a modernidade está sempre a olhar para trás, reconhecendo a força de acontecimentos que, embora "adormecidos" no passado, permanecem atuando no presente.

A partir desta perspectiva ontológica, cada face desvela significados e formas variadas de se expressar no mundo. Através de um exercício transformador de si que compõe toda uma estética da existência (Foucault, 1984/2003a), as várias faces dessas mulheres contemporâneas se encontram em um movimento dinâmico de apreensão da maternidade em seus múltiplos processos de subjetivação.

Ao contrário de um padrão único e homogêneo de maternidade, emergiram várias faces interpostas, permeáveis, passíveis de transformação em um movimento dinâmico e contínuo de ser-mãe. Atrevemo-nos a parafrasear Foucault (1969/2008), assinalando que cada uma das entrevistadas poderia afirmar, a partir de seus posicionamentos diante da experiência (ou não) de maternidade: "Não me pergunte quem sou e não me diga para permanecer a mesma".

O estudo não se pretendeu exaustivo, dado seu caráter exploratório de tema bastante complexo. Outros perfis de mães que não foram diretamente explorados pela pesquisa, como as mães adotivas, em processo de reprodução assistida ou em arranjos homoafetivos apresentam-se como importantes campos a serem investigados. Espera-se, entretanto, que a presente pesquisa possa servir como referência para outras linhas de práxis e estudos que se dediquem às mulheres e à maternidade contemporânea, tendo-se em vista as suas múltiplas possibilidades de subjetivação. 


\section{Referências}

Badinter, E. (2011). O conflito. A mulher e a mãe. Rio de Janeiro: Record.

Badinter, E. (1985). Um amor conquistado: o mito do amor materno. Tradução de Waltensir Dutra. Rio de Janeiro: Nova Fronteira.

Polity, E., \& Balestrero, A. (2008). A mulher e a maternidade. In V. Meirelles (Org.), Mulher do Século XXI (pp. 111-128). São Paulo: Roca.

Bardin, L. (2011). Análise de Conteúdo, 2a ed. Lisboa: Edições 70.

Coelho, S. V. (2006). As transformações da família no contexto brasileiro: uma perspectiva das relações de gênero. In J. G. Aun, M. J. E. de Vasconcellos, \& S. V. Coelho (Orgs.), Atendimento Sistêmico de Famílias e Redes Sociais, Vol. I: Fundamentos Teóricos (pp. 152-164). Belo Horizonte: Ophicina de Arte e Prosa.

Collin, F., \& Laborie, F. (2009). Maternidade. In H. Hirata et al. (Orgs.), Dicionário crítico do feminismo (pp. 133-138). São Paulo: Editora Unesp.

Druckerman, P. (2013). Crianças francesas não fazem manha. Tradução de Regiane Winarski. Rio de Janeiro: Objetiva.

Foucault, M. (2006). A hermenêutica do sujeito. 2. ed. Edição estabelecida por Frédéric Gros sob a direção de François Ewald e Alessandro Fontana. Tradução de Márcio Alves da Fonseca e Salma Tannus Muchail. São Paulo: Martins Fontes. (Seminário original em 1981-1982).

Foucault, M. (2004). A Ética do Cuidado de Si como Prática da Liberdade. In Ética, Sexualidade, Política [Coleção Ditos e Escritos, vol. V] (pp. 264-287). Rio de Janeiro: Forense Universitária. (Entrevista original em 1984).

Foucault, M. (2002). História da sexualidade 3: o cuidado de si. Rio de Janeiro: Edições Graal. (Original publicado em 1984).

Foucault, M. (2003). História da sexualidade 2: o uso dos prazeres (10 a ed.). Rio de Janeiro: Edições Graal. (Original publicado em 1984).

Foucault, M. (1995). O sujeito e o poder. In: H.L. Dreyfus, \& P. Rabinow. Michel Foucault: Uma Trajetória Filosófica - para além do estruturalismo e da hermenêutica (7ạ ed.) (pp. 231-249). Rio de Janeiro: Forense Universitária.

Foucault, M. (2002). Nietzsche, a genealogia e a história. In M. Foucault, Microfísica do Poder (pp. 15-37). 17a ed. São Paulo: Graal (Obra original publicada em 1971).

Giddens, A. (1993). A transformação da intimidade: sexualidade, amor e erotismo nas sociedades modernas. São Paulo: Editora UNESP. 
Gutman, L. (2013) Mulheres visíveis, mães invisíveis. Rio de Janeiro: BestSeller.

Jovchelovitch, S., \& Bauer, M. W. (2002). Entrevista narrativa. In M. W. Bauer, \& M. W. G. Gaskell. Pesquisa qualitativa com texto, imagem e som (pp. 90-113). Petrópolis, RJ : Vozes.

Lima, A. de B. B. do C. (2005). "De Maria a Mary - "Mulheres em transição" na experiência contemporânea da maternidade. (Tese de Doutorado). Universidade Federal do Rio de Janeiro, Programa de Pós-Graduação em Estudos Interdisciplinares de Comunidades e Ecologia Social, Rio de Janeiro. Recuperado em 24 de fevereiro de 2011, de http: //pos. eicos. psicologia.ufrj. br/wpcontent/uploads/angelinadebelli.pdf

Mello, I. S. P. B. de. (2011). Amor materno: mito ou realidade? Recuperado em 05 de janeiro, 2011 de http://www.escolafreudianajp.org/arquivos/trabalhos/Amor_ma terno_mito_ou_realidade.pdf

Méllo, R. P., \& Di Paolo, (2007). Subjetivações, identidades e o linguajar. Estudos e Pesquisas em Psicologia, 7(3), 131-142.

Rose, N. (2011). Inventando nossos selfs: Psicologia, poder e subjetividade. Petrópolis, RJ : Vozes.

Scavone, L. (2001). A maternidade e o feminismo: diálogo com as ciências sociais. Cadernos Pagu, (16), 137-150. Recuperado em 08 de agosto, 2012 de http://dx.doi.org/10.1590/S010483332001000100008

Souza, E de. Bandeiras feministas na luta pela igualdade de gênero. Revista Espaço Acadêmico, [S.I.], n. 108, maio 2010. Recuperado em 01 de fevereiro, 2013 de http://periodicos. uem. br/ojs/index. php/EspacoAcademico/articl e/viewFile/8865/5621

Spink, M. J. P. (2010). Álbuns de bebê: reflexões sobre tecnologias que performam pessoalidades. In S. J. Souza, \& M. Moraes, Marcia (Orgs.), Tecnologias e Modos de Ser no Contemporâneo (pp. 25-52). Rio de Janeiro: Ed. PUC-Rio, 7 Letras.

Stasevskas, K. O. (1999). Ser mãe: narrativas de hoje. (Dissertação de Mestrado). Faculdade de Saúde Pública, Universidade de São Paulo, São Paulo. Recuperado em 24 de fevereiro de 2011, de http://www.teses.usp. br/teses/disponiveis/6/6136/tde-

16032005-141212/ 


\section{Endereço para correspondência}

\section{Renata Feldman Scheinkman Lemos}

Feldman Clínica de Psicologia

Rua do Ouro, 104 sl. 804, Serra, CEP 30220-000, Belo Horizonte - MG, Brasil

Endereço eletrônico: rfeldman@globo.com

\section{Luciana Kind}

Pontifícia Universidade Católica de Minas Gerais - PUC Minas

Avenida Itaú, 525, Prédio Redentoristas, Dom Cabral, CEP 30535-012, Belo Horizonte - MG, Brasil

Endereço eletrônico: lukind@gmail.com

Recebido em: 03/09/2015

Reformulado em: 27/04/2017

Aceito em : 27/04/2017

\section{Notas}

* Psicóloga. Mestre em Psicologia pela PUC Minas. Autora dos livros Amor em Pedaços e Refúgio, além do blog www.renatafeldman.com.br. Professora universitária, palestrante e psicoterapeuta humanista com foco nas relações afetivas. Coordenadora da Feldman Clínica de Psicologia.

** Doutorado em Saúde Coletiva (IMS/UERJ). Pós-doutorado em Psicologia Social (UFMG). Professora do Programa de Pós-graduação em Psicologia da PUC Minas. Coordenadora do grupo de pesquisa Narrativas, Gênero e Saúde (NaGeS): www.grupo-nages.org

Este artigo de revista Estudos e Pesquisas em Psicologia é licenciado sob uma Licença Creative Commons Atribuição-Não Comercial 3.0 Não Adaptada. 